\title{
Composition and thermal analysis of lipids from pre-fried chicken nuggets.
}

\begin{abstract}
Composition and thermal profiles of the endogenous lipids of ten commercial chicken nuggets brands (NPO, ACO, AFO, APO, ASO, AMO, ARO, JOD, SMO, and SOD) were compared with those of the lipids of chicken nuggets pre-fried in lard (ALD) and palm olein (AOO) to determine the type of oil used for pre-frying of the product. The stearic acid content of the commercial brands were similar to that of the sample pre-fried in palm olein, but significantly $(\mathrm{p}<0.05)$ lower than that of the sample pre-fried in lard. The triacylglycerol (TAG) profiles of the commercial brands were similar to that of the sample pre-fried in palm olein, but distinctly different from the sample pre-fried in lard according to the dissimilarities in the contents of TAG molecules namely, PLL, POS, and PPO. Based on thermal analysis, the commercial brands of chicken nuggets could be divided into three distinguishable subgroups namely, Group-A: NPO; Group-B: ACO, AFO, APO, ASO; Group-C: AMO, ARO, JOD, SMO, SOD. While brands under group-B showed close similarity to AOO, none show any similarity to sample ALD. As any of the samples did not possess characteristics of the sample pre-fried in lard, the commercial brands of chicken nuggets of this study are recommendable for consumers whose religious restriction prevents the use of lard in food.
\end{abstract}

Keyword: Chicken nuggets; Differential scanning calorimetry; Frying oil; Lard detection; Palm olein; Thermal analysis. 